\title{
Políticas públicas para formação de tecnólogos no Brasil
}

\author{
Public policies for training technologist in Brazil
}

\section{Políticas públicas para formación de tecnólogos en Brasil}

\author{
Anthone Mateus Magalhães Afonso" \\ Instituto Federal de Educação, Ciência e Tecnologia Fluminense (IF Fluminense), Campos \\ dos Goytacazes, Professor do Ensino Básico, Técnico e Tecnológico \\ Wania Regina Coutinho Gonzalez ${ }^{2}$ \\ Universidade Estácio de Sá, Professora do Programa de Pós-Graduação em Educação;
}

Resumo: Neste estudo analisaram-se as políticas públicas educacionais voltadas para os Cursos Superiores de Tecnologia (CSTs) desde o início da sua oferta, na década de 1960, identificando, entre outros aspectos, as concepções de educação adotadas nesse período de estudo e os enfrentamentos das instituições públicas de educação profissional a essas políticas. São consideradas as contribuições de Marisa Brandão, Acácia Kuenzer e Neise Deluiz para efetuar uma análise a partir de pesquisa documental que identificou o surgimento dos cursos de graduação de curta duração e traçou a concepção inicial dos CSTs, seguindo com as políticas nacionais criadas a partir da década de 1990 até o segundo Governo do Presidente Fernando Henrique Cardoso (FHC). Os resultados obtidos revelaram algumas constatações, dentre as quais se destacam: em todo o período compreendido nesta pesquisa o modelo legal proposto para os CSTs promovia uma educação voltada para o mercado de trabalho; a retomada da oferta dos CSTs pelos Governos FHC sinaliza um modelo de política pública que parecia trazer a execução antes do planejamento, o que ocasionou alguns efeitos desastrosos, como baixa aceitação dos profissionais formados e dificuldade para continuidade dos estudos acadêmicos em nível de pós-graduação e para ocupação das suas

Doutor em Educação pela Universidade Estácio de Sá; Mestre em Engenharia Mecânica Controle e Automação pela Universidade Federal Fluminense.

2 Doutora em Educação pela Universidade Federal do Rio de Janeiro; Mestre em Educação pela Fundação Getúlio Vargas. 
funções profissionais de trabalho, uma vez que a oferta dos cursos ocorreu antes mesmo da sua completa regulação.

Palavras-chave: Cursos Superiores de Tecnologia. Políticas Públicas. Educação Profissional e Tecnológica. Concepção de Educação.

Abstract: The article analyzes the educational public policies directed to Technologist Training Degrees (CSTS) since the beginning of its offer in the 1960s, identifying, among other aspects, the conceptions of education adopted in this period of study and the confrontations of public institutions education to these policies. The contributions of Marisa Brandão, Acácia Kuenzer and Neise Deluiz are considered to carry out an analysis based on documentary research that identified the emergence of the short duration undergraduate courses and outlined the initial conception of the CSTs, following the national policies created from the 1990 until the second Government of President Fernando Henrique Cardoso (FHC). The results obtained revealed some findings, among which the following stand out: throughout the period included in this study, the legal model proposed for CSTs promoted an education focused on the labor market; the resumption of CSTs by the Governments of FHC signaled a public policy model that seemed to bring execution before planning, causing some disastrous effects, such as low acceptance of trained professionals and difficulty in continuing academic studies at the level of postgraduate studies and to occupy their professional work functions since the course offerings occurred before their complete regulation.

Keywords: Technologist Training Degrees. Higher Education Courses in Technology. Public policy. Technical and Vocational Education and Training. Conception of Education.

Resumen: El artículo analiza las políticas públicas educativas dirigidas a los Cursos Superiores de Tecnología (CST) desde el inicio de su oferta, en la década de 1960, identificando, entre otros aspectos, las concepciones de educación adoptadas en ese período de estudio y los enfrentamientos de las instituciones públicas de educación profesional a esas políticas. Se consideran las contribuciones de Marisa Brandão, Acacia Kuenzer y Neise Deluiz para efectuar un análisis a partir de investigación documental que identificó el surgimiento de los cursos de graduación de corta duración y trazó la concepción inicial de los CSTS, siguiendo con las políticas nacionales creadas a partir de la política 
nacional en la década de 1990 hasta el segundo Gobierno del Presidente Fernando Henrique Cardoso (FHC). Los resultados obtenidos revelaron algunas constataciones, entre las cuales se destacan: en todo el período comprendido en esta investigación el modelo legal propuesto para los CSTs promovía una educación orientada al mercado de trabajo; la reanudación de la oferta de los CST por los Gobiernos de FHC señala un modelo de política pública que parecía traer la ejecución antes de la planificación, lo que ocasionó algunos efectos desastrosos, tales como baja aceptación de los profesionales formados y dificultad para la continuidad de los estudios académicos a nivel de postgrado y para ocupar sus funciones profesionales de trabajo una vez que la oferta de los cursos se dio antes incluso de su completa regulación.

Palabras clave: Cursos Superiores de Tecnología. Políticas públicas. Educación Profesional y Tecnológica. Concepción de Educación.

\section{INTRODUÇÃO}

A oferta dos Cursos Superiores de Tecnologia (CSTs) no Brasil teve início a partir de políticas públicas desenvolvidas nas décadas de 1960 e 1970 para implantação de cursos superiores de curta duração.

Após o desenvolvimento de várias ações para ampliação da oferta desses cursos superiores de curta duração, no final da década de 1970, as políticas de incentivo a essa formação foram descontinuadas, sendo retomadas apenas na década de 1990.

Nesse contexto de oferta e ruptura de um modelo de educação profissional tecnológica de graduação no Brasil, o objetivo com este trabalho foi analisar as políticas públicas educacionais voltadas para os CSTs desde o início da sua oferta (na década de 1960) até o final do segundo Governo do Presidente Fernando Henrique Cardoso (FHC), em 01 de janeiro de 2003, identificando, entre outros aspectos, a concepção de educação presente nesse período de estudo e os enfrentamentos das instituições públicas de educação profissional a essas políticas. 


\section{SURGIMENTO DOS CURSOS SUPERIORES DE TECNOLOGIA: UM BREUE HISTÓRICO}

A formação profissional tecnológica de nível superior começou a ser ofertada no Brasil na década de 1960 como parte de políticas nacionais de modernização associadas ao capital estrangeiro. No início dessa década emergiram discussões sobre a necessidade da reformulação do ensino superior no Brasil, e algumas propostas governamentais foram apresentadas para oferta de cursos de graduação diferentes dos tradicionais, com duração mais curta.

Em 1968, com a publicação da Lei n. 5.540, de 28 de novembro, instituiu-se a Reforma Universitária no Brasil, que abriu formal e legalmente o espaço para a oferta de cursos superiores de curta duração. Trata-se do marco legal necessário para legitimar e ampliar a oferta de cursos superiores de formação intermediária para atender aos interesses do capital nacional e internacional no Brasil. De acordo com o artigo 23 dessa Lei, "Art. 23. Os cursos profissionais poderão, segundo a área abrangida, apresentar modalidades diferentes quanto ao número e à duração, a fim de corresponder às condições do mercado de trabalho." (BRASIL, 1968). E, no parágrafo primeiro desse mesmo artigo, define-se: "Art. 23. § $1^{\circ}$ Serão organizados cursos profissionais de curta duração, destinados a proporcionar habilitações intermediárias de grau superior." (BRASIL, 1968).

A partir dessas definições, outras diferentes propostas que estavam em estudo no País se concretizaram, além da Engenharia Operacional que já era ofertada. Surgiram, então, os cursos técnicos de nível superior, posteriormente chamados de Cursos Superiores de Tecnologia. (CSTs).

Em 1971, a partir de um acordo do Ministério da Educação e Cultura (MEC) com o Banco Internacional de Reconstrução e Desenvolvimento (BIRD), ocorreu um empréstimo nesse banco para financiamento de um programa de ensino médio profissional e ensino superior de curta duração, incluindo a construção de prédios, laboratórios e a aquisição de equipamentos para essa oferta, bem como a preparação de recursos humanos. Para Brandão (2013, p. 
319), "tratava-se do avanço daquele projeto inicial - educacional, com base em determinado modelo econômico - defendido pela Fundação Ford e adotado pelo regime militar e pelos dirigentes que lhe representavam."

Em junho desse mesmo ano foi instituída a Comissão de Administração do Programa de Ensino Médio (Profissional) e Superior de Curta Duração (Engenharia Operacional), ligada ao Departamento de Ensino Médio (DEM). Tratava-se de um programa (conhecido como PRODEM) criado para assumir os objetivos firmados com o BIRD. Esse mesmo projeto tinha a incumbência de cuidar do ensino profissional médio e do ensino superior de curta duração.

Verifica-se que a responsabilidade pela expansão, implantação e execução das políticas públicas era do Departamento de Assuntos Universitários (DAU), enquanto a execução e realização das tarefas previstas no convênio MEC/BIRD I era do DEM, que tratava, no âmbito do MEC, das ações ligadas ao ensino médio, o que gerava uma grande contradição: esses cursos intermediários ditos de nível superior eram, afinal, equivalentes a cursos de graduação?

Tal contradição inicial na organização do MEC para a oferta desses cursos contribuía para a indefinição da resposta a essa e a outras perguntas relacionadas à valorização e ao reconhecimento dos profissionais egressos que margeavam entre a formação em um curso técnico pós-médio (conforme proposto pela Fundação Ford com a transferência do modelo americano no início da década de 1960) ou curso superior de curta duração, como as engenharias de operação (ao que parece uma transformação do modelo traduzido para atender às pressões e necessidades do País).

A denominação Cursos Superiores de Tecnologia passou a ser adotada oficialmente apenas em 1973, quando o Conselho Federal de Educação (CFE) emitiu o Parecer n. 1.060/73 sobre a formação de técnicos de nível superior. $\bigcirc$ Parecer afirmava que:

Parece conveniente que os cursos técnicos de nível superior na área da Tecnologia passem a ser chamados "Cursos Superiores de Tecnologia", dando-se aos diplomados pelos mesmos a denominação de "Tecnólogos". A 
primitiva denominação é muito extensa e até o presente tem dado alguma confusão com os "Técnicos de Nível Médio", apesar do qualitativo "de Nível Superior". De outro lado, a denominação de "Tecnólogo" [como vêm sendo ultimamente chamados], além de concisa, parece traduzir melhor o profissional diplomado por instituição que objetive a formação de especialista em determinado ramo da tecnologia. (BRANDÃO, 2013, p. 321).

Em 1975, o CFE aprovou o Parecer n. 1.589/75, que tratava da criação dos Centros de Educação Tecnológica, com base em um documento encaminhado pelo DAU. Era a sinalização da opção pela implantação de Centros de Tecnologia como o criado anteriormente pelo Governo do Estado de São Paulo (Centro Estadual de Educação Tecnológica de São Paulo, mais tarde chamado de Centro Estadual de Educação Tecnológica Paula Souza). E foi a partir dessa aprovação que o MEC organizou um Centro Tecnológico para oferta de Cursos Superiores de Tecnologia de curta duração no Estado da Bahia, em convênio com a Fundação Centro de Educação Técnica da Bahia (Ceteba), uma instituição estadual. Surgia, então, o Centro de Educação Tecnológica da Bahia (Centec-BA), o primeiro centro criado em nível federal, a partir da Lei n. 6.344, de 06 de julho de 1976 (BRASIL, 1976). "A esse Centro caberiam, de acordo com a lei, exclusivamente, atividades voltadas para os cursos superiores de tecnologia (ou de formação de tecnólogos), destacando-se aí a caracterização destes cursos - intensivo e terminal." (BRANDÃO, 2013, p. 323).

Em 1978, com a criação de três Centros Federais de Educação Tecnológica (CEFETs) a partir da transformação das escolas técnicas de Minas Gerais, do Paraná e Celso Suckow da Fonseca (BRASIL, 1978), o MEC concretizou o previsto no acordo com $\circ$ BIRD, efetivando duas políticas de cursos superiores de curta duração: os de Engenharia Operacional e os de Tecnologia. Posteriormente, ainda no final dos anos 1970, essas políticas foram descontinuadas, os cursos de Engenharia de Operação substituídos pelos de Engenharia Industrial de graduação plena e os CSTs passaram a perder atratividade em razão da falta de apoio para regulamentação da profissão, definição de atribuições junto aos conselhos de classe, entre outras dificuldades em reconhecê-los como de nível superior - de graduação. 
No início da década de 1990, após longo período com oferta reduzida dos CSTs e sem a implantação de políticas públicas de incentivo à sua ampliação, o MEC desenvolveu alguns trabalhos e desencadeou ações para a retomada desses cursos como parte de um plano para readequação da educação profissional.

Entre essas ações, no Governo Collor, ${ }^{3}$ em 1991, a Secretaria Nacional de Educação Tecnológica (Senete), atual Secretaria de Educação Profissional e Tecnológica (Setec), elaborou a proposta de criação de um Sistema Nacional de Educação Tecnológica, em paralelo ao Sistema Nacional de Educação.

A criação de dois sistemas nacionais de educação evidenciava a dualidade entre sistemas de ensino diferenciados para a classe dirigente e a classe trabalhadora. Era a "reafirmação de um dos princípios básicos da velha escola dual: para os pobres e desvalidos, deficientes e marginalizados, a escola do trabalho e o exercício de funções subalternas no processo produtivo." (KUENZER, 2007, p. 47).

Pela proposta, o Sistema Nacional de Educação Tecnológica deveria abranger as instituições de ensino do setor público federal, estadual e municipal das instituições particulares envolvidas na oferta de educação tecnológica, incluindo o Serviço Nacional de Aprendizagem Industrial (Senai) e o Serviço Nacional de Aprendizagem Comercial (Senac), ofertando as seguintes modalidades: qualificação profissional sem exigências de escolarização prévia, educação profissional com exigências de escolarização no âmbito do ensino fundamental, ${ }^{4}$ formação técnica de nível médio, formação técnica de nível superior -abrangendo a qualificação de tecnólogos e formação profissional superior destinada aos cursos plenos.

No que se refere especificamente aos CSTs, observa-se a defesa de uma formação técnica de nível superior voltada para a prática, de modo

\footnotetext{
3 O Governo do Presidente Fernando Collor de Mello teve início em 15 de março de 1990 e encerramento em 29 de dezembro de 1992 quando renunciou ao cargo em meio ao processo de impeachment que fora aberto em 01 de outubro do mesmo ano, causando seu afastamento no dia seguinte. Assumiu em seu lugar para continuidade do governo o então vice-Presidente Itamar Franco (1992-1994).

4 Utilizamos a terminologia vigente na legislação atual.
} 
diferenciado dos cursos superiores plenos oferecidos pelas universidades, que deveriam proporcionar uma formação geral mais abrangente e preparar tanto para o exercício profissional quanto para a investigação científica, reforçando a dualidade educacional para além da divisão dos sistemas nacionais de educação, ou seja, ratificando a dualidade entre os cursos de mesmo nível, superior.

A proposta desse Sistema Nacional de Educação Tecnológica deixa claro o retorno ao princípio educativo humanista clássico. Nos CSTs isso fica evidente na defesa de "um forte componente 'prático' em detrimento do 'científico', como se fosse possível técnica sem ciência." (KUENZER, 2007, p. 45).

Outro aspecto sobre esse Sistema Nacional de Educação Tecnológica é a proposta de verticalização do ensino, de modo que é assegurada a continuidade dos estudos dentro do próprio sistema, do primeiro grau à pós-graduação, estabelecendo "um continuum de oferta de ensino com rígida seletividade, na formação de recursos humanos na área tecnológica" (KUENZER, 2007, p. 48), perpetuando as diferenças sociais. A referida proposta contraria os princípios da escola unitária de Gramsci que havia denunciado a dualidade educacional, no século XX, na Itália, e defendia um tipo único de escola preparatória (elementar-média) que conduziria os jovens para a escola profissional, evitando a multiplicação e graduação dos tipos de escolas profissionais (GRAMSCI, 1978).

Em outro documento da Senete, dedicado aos CSTs, é ratificada a defesa do Sistema Nacional de Educação Tecnológica e apresentada de forma mais detalhada uma proposta para oferta desses cursos superiores (BASTOS, 1991b). ${ }^{6}$ É resgatada a origem dos CSTs nas décadas de 1960 a 1980, enumeradas as

\footnotetext{
5 Nomenclatura utilizada na época, posteriormente alterada para ensino fundamental.

6 A proposta específica para os CSTs (BASTOS, 1991b), assim como a destinada para a educação técnico-profissional de uma forma mais geral (BASTOS, 1991a), publicadas pela Senete, foi escrita pelo professor João Augusto de Souza Leão de Almeida Bastos, o qual é responsável pela implantação de diversos CSTs no País. Ele foi Assessor Especial para Assuntos Universitários e Coordenador do Programa Nacional dos Cursos de Tecnólogos (1972-1975), primeiro diretor do Centec-BA (instituição inicialmente dedicada exclusivamente à oferta de cursos de graduação tecnológica), analista e assessor em diversos projetos do Conselho Nacional de Desenvolvimento Científico e Tecnológico (CNPq). Atualmente é professor da Universidade Tecnológica Federal do Paraná (UTFPR).
} 
principais dificuldades encontradas e tecidas algumas críticas à falta de políticas públicas e investimentos para a manutenção de oferta dos cursos.

Dentre as dificuldades que perduravam até a década de 1990, Bastos (1991b, p. 24) cita: "rejeição por parte do mercado de trabalho; não aceitação pelas instituições, órgãos de classe e profissionais e pelas próprias empresas; número crescente de alunos desejando continuar seus estudos em nível de graduação, etc."

Se em documentos legais já apresentados e discutidos anteriormente existia certa confusão entre o modelo de formação proposto pela Fundação Ford e o efetivamente adotado, regulamentado e ofertado no Brasil, verifica-se nesse documento da Senete que a proposta era mesmo a de cursos de nível superior em relação ao técnico de nível médio, mas inferior ao do graduado na universidade. Esse posicionamento fica claro na proposta da Senete ao afirmar:

Os cursos superiores de tecnologia proporcionam habilitações intermediárias de nível superior, em modalidades específicas e profissionalizantes. Para melhor situar o técnico de nível superior no âmbito do quadro profissionalizante, à guisa de esclarecimento, vale identificá-lo a partir de três níveis de formação profissional: o técnico de nível médio; o técnico de nível superior; o profissional graduado pela universidade [...] Esta modalidade de educação superior oferece aos indivíduos competências e qualificações, para as quais os estudos universitários tradicionais situam-se em nível mais elevado e teórico, enquanto o ensino de grau médio revela-se insuficiente para atender a gama complexa das aplicações tecnológicas. (BASTOS, 1991b, p. 12, 14).

Dessa forma, a partir da proposta de um sistema nacional de educação dual, conforme exposto anteriormente, apresentavam-se nessa concepção de educação profissional níveis de escolarização próprios, que caracterizavam e definiam o ensino profissional em diferentes níveis, mas que nem mesmo no seu mais alto nível se considerava igual ao nível promovido pela graduação universitária, aproximando esse modelo proposto ao americano formatado pela Fundação Ford. 
Porém, são evidenciadas algumas diferenças entre o modelo implantado no Brasil e o proposto pela Fundação Ford: desde o momento inicial de oferta, os documentos legais referenciavam esses cursos tecnológicos como superiores, algo diferente do observado em outros países onde essa modalidade era ofertada, geralmente chamada simplesmente de formação pós-média ou pós-técnica, mas não de técnica de nível superior.

Além de propor uma formação intermediária, não equivalente ao nível do graduado pela universidade, a Senete defendia que essa formação fosse voltada para as tarefas de execução, como as desenvolvidas pelos técnicos de nível médio, no contexto das atividades práticas, deixando para os profissionais graduados nos cursos plenos das universidades as tarefas de investigação científica e desenvolvimento de pesquisa. Os tecnólogos deveriam, então, desenvolver tarefas técnicas e tecnológicas mais específicas e que exigissem maior conhecimento do que as desenvolvidas pelos técnicos de nível médio, mas sem deter as prerrogativas da pesquisa e investigação científica que seriam destinadas aos graduados nas universidades.

O desenrolar dos fatos ao longo da década de 1990 mostrará o caminho escolhido e as preferências governamentais para a graduação tecnológica no Brasil a partir dessas proposições da Senete/MEC.

\section{A RETOMADA DA OFERTA DE CSTS NA DÉCADA DE 1990}

Uma importante ação para a retomada da oferta dos CSTs ocorreu ainda no Governo do Presidente Itamar Franco. Após o conjunto de publicações com proposições da Senete/MEC e aliado ao modelo de desenvolvimento econômico emergente da década de 1990, as Escolas Técnicas Federais (ETFs) foram transformadas em CEFETs (Centros Federais de Educação Tecnológica) por meio da Lei n. 8.948, de 08 de dezembro de 1994 (BRASIL, 1994), instituindo - Sistema Nacional de Educação Tecnológica. A partir dessa transformação seria possível a oferta de cursos de nível superior nessas novas instituições. 
Essa Lei também garantia, no parágrafo $1^{\circ}$ do artigo $1^{\circ}$, a possibilidade de participação da rede particular no Sistema Nacional de Educação Tecnológica que então era criado: "Art. $1^{\circ}$. [...] § $1^{\circ}$ A participação da rede particular no Sistema Nacional de Educação Tecnológica poderá ocorrer, ouvidos os respectivos órgãos superiores deliberativos." (BRASIL, 1994).

Para Brandão (2013), naquele momento formalizava-se o que parecia ser uma nova política para a educação profissional e para essas instituições, mas observa que não se tratava exatamente de uma novidade, recordando da relação entre os cursos de engenharia de operação e a política de cursos superiores de curta duração dos anos 1960 e 1970.

Apesar de a Lei n. 8.948 determinar que os novos CEFETs deveriam ter a mesma regulamentação dos mais antigos, ou seja, CEFET BA, CEFET MA, CEFET MG, CEFET PR e CEFET RJ, ${ }^{7}$ definia também que as providências necessárias para a execução dessa Lei ocorreriam mediante decreto de regulamentação a ser publicado em até 60 dias. No entanto, o decreto foi assinado e publicado apenas três anos após a publicação dessa Lei, em 1997 Decreto n. 2.406, de 27 de novembro de 1997 (BRASIL, 1997c) - já no primeiro Governo FHC, "no contexto de uma série de decretos na área educacional que vieram antes e após a promulgação de nossa nova Lei de Diretrizes e Bases da Educação (LDB), de 1996." (BRANDÃO, 2013). Dessa forma, apesar da transformação das ETFs em CEFETs desde 1994, suas prerrogativas de atuação a partir da nova formatação (dentre elas a oferta de alguns cursos superiores) somente foram possíveis em 1997, após um conjunto de reformas executadas pelo Governo FHC em toda a educação, incluindo profundas mudanças no campo da EPT.

Esse movimento de mudanças na EPT, iniciado no Governo Collor, passando por Itamar Franco e depois por FHC, redefiniu a oferta da educação técnica de nível médio e retomou a oferta da graduação tecnológica de curta duração no Brasil. Essas ações fizeram parte de uma grande reforma da educação profissional baseada em um discurso global patrocinado por agências

7 Criados pela Lei n. 6.545/1978 (BRASIL, 1978), o Decreto n. 87.310/1982 (BRASIL, 1982), que a regulamenta, e a Lei n. 8.71 l/1993 (BRASIL, 1993), que cria o CEFET BA e modifica a própria Lei n. 6.545/1978, ampliando a possibilidade de ensino superior nessas instituições. 
internacionais e voltada para o desenvolvimento econômico do País. Estavam em jogo a necessidade de atendimento rápido às demandas do mercado por mão de obra, bem como a urgência de expansão do ensino superior, com forte adesão e participação das instituições de ensino privadas, inclusive em outros níveis de ensino da educação profissional.

Um ponto chave dessas mudanças, marco das investidas governamentais na reformulação da educação profissional, é a publicação da LDB em 20 de dezembro de 1996 (BRASIL, 1996) no Governo FHC.

A Lei tratava da EPT nos parágrafos $2^{\circ}$ e $4^{\circ}$ do artigo 36, em que se definiam as diretrizes do ensino médio e se previa a possibilidade de preparação para o "exercício de profissões técnicas", sendo facultada uma "habilitação profissional" a ser desenvolvida "nos próprios estabelecimentos de ensino médio ou em cooperação com instituições especializadas em educação profissional." (BRASIL, 1996).

Foi destinado, ainda, um capítulo específico para a educação profissional: "Capítulo III - Da Educação Profissional", quando definiram de forma simples e pouco objetiva os princípios para a educação profissional no Brasil, nos artigos 39 a 42 .

Além de não definir de forma clara aspectos importantes da educação profissional e tecnológica, são mencionados apenas alguns aspectos da educação profissional técnica de nível médio. Já os CSTs não foram referenciados nesses artigos destacados, nem mesmo no Capítulo IV, que tratava da educação superior, ou seja, ficou ausente tanto nas definições da educação profissional quanto na educação superior. Cabe registrar que àquela época a LDB/1996 não utilizava o termo "educação profissional e tecnológica", mas apenas "educação profissional".

As definições que não existiam na LDB/1996, mas que eram necessárias à EPT e à educação brasileira nos diferentes níveis de ensino, somente foram determinadas de forma temporária/transitória mediante decretos, portarias ministeriais ou resoluções, ou de forma definitiva por meio de outras leis complementares nos anos seguintes. 
A esse respeito, observa-se em todo o período dos Governos FHC a utilização de muitos instrumentos temporários, utilizados como forma de imposição rápida e imediata, sem grande discussão e participação da sociedade e das suas representações. Esse fluxo somente foi alterado com base em instrumentos de regulação definitivos da própria LDB durante o primeiro mandato do Presidente Lula.

São observados, ao longo da história, vários casos em que decretos, portarias e resoluções não foram utilizados como complementos, mas como "atalhos" para implementação de políticas de governo de forma imediata, facilitada e transitória. Um desses casos, que gerou grande impacto na educação profissional, compreende a publicação do Decreto n. 2.208, de 17 de abril de 1997 (BRASIL, 1997b), no qual o Governo FHC regulamentou o parágrafo $2^{\circ}$ do artigo 36 e os artigos 39 a 42 da Lei n. 9.394, de 20 de dezembro de 1996 (BRASIL, 1996), ou seja, definiu de forma direta e objetiva, mas sem ampla discussão com a sociedade, pontos ausentes ou que não estavam claros no texto da LDB. Nesse Decreto, foram determinados os objetivos da educação profissional, suas formas de articulação, seus níveis, diretrizes curriculares, formas de estruturação dos currículos e outros aspectos.

Ausente na LDB/ 1996, a definição dos níveis da educação profissional também foi estabelecida a partir do Decreto n. 2.208/1997 (BRASIL, 1997b), artigo $3^{\circ}$, determinando a sua oferta em três níveis - básico, destinado tanto à qualificação quanto a reprofissionalização dos profissionais, sem exigências de escolaridade; técnico, direcionado à habilitação de alunos e concluintes do ensino médio e técnico; e tecnológico, abrangendo os cursos de nível superior no âmbito da educação tecnológica.

Essa definição dos níveis da educação profissional promoveu o surgimento de um novo nível, o nível tecnológico, uma novidade nos documentos legais da educação brasileira. Mas o que seria esse nível tecnológico? Seria esse nível equivalente ao de graduação? Durante alguns anos essas perguntas continuaram sem respostas claras e consistentes, principalmente no que diz respeito ao aparato legal da educação. 
Mesmo com os problemas enfrentados desde a década de 1970 com os cursos superiores de graduação de curta duração e com os vários questionamentos e discussões travados no intuito de fortalecer a oferta desses cursos e obter maior valorização junto aos empregadores, conselhos de classe, comunidade acadêmica e sociedade de modo geral, o Decreto supracitado inova criando um nível até então desconhecido e que mais uma vez não é equiparado legalmente e de forma clara aos cursos de graduação existentes. Pela definição no Decreto, trata-se de um nível específico da formação profissional, considerado superior na área tecnológica e destinado aos egressos do ensino médio e técnico. Ou seja, uma formação superior à técnica de nível médio, mas que se enquadrava em um nível que somente existia na educação profissional: o nível tecnológico. Tratavase da formalização da oferta de uma formação intermediária que se aproximava mais uma vez da defendida em décadas anteriores pela Fundação Ford, como empregada no modelo americano.

No artigo 10 do referido texto legal é mencionado que os CSTs correspondem à educação profissional de nível tecnológico, a sua organização deve atender às demandas de formação dos diferentes setores da economia e os seus concluintes serão portadores de diploma de Tecnólogo. Se por um lado não foi utilizado o termo "técnico de nível superior", conforme já havia sido recomendado no Parecer n. 1.060/73 do CFE desde a década de 1970, o que poderia gerar confusões a respeito dos cursos, por outro, essa formação ficava enquadrada em um nível até então inexistente no sistema educacional brasileiro. Ou seja, um novo nível no novo Sistema Nacional de Educação Tecnológica que surgira em 1994 no Governo Itamar Franco sob forte crítica de pesquisadores brasileiros, conforme apresentado anteriormente.

Esse enquadramento em um nível que, pode-se dizer, não existia no sistema de ensino tradicional, associado à falta de definição na lei maior de diretrizes e bases da educação nacional - estando apenas tratado em um decreto específico para a educação profissional e que também não estabelecia a equiparação com os cursos de graduação tradicionais, ocasionou grande rejeição por parte do mercado de trabalho, conselhos de classe e sociedade de modo geral. Seja pelo desconhecimento geral ou por entender que se tratava de uma formação intermediária não equiparada aos cursos de graduação 
tradicionais, os egressos dos CSTs passaram por um período de grande rejeição tanto no campo acadêmico quanto no campo empresarial/industrial. Eram comuns os casos de egressos que não conseguiam dar prosseguimento aos estudos em nível de pós-graduação ou que eram contratados e remunerados como técnicos, em um nível abaixo de sua formação. Parecia haver uma consonância nessa época de que esses cursos de tecnólogos eram cursos apenas tecnológicos, que não garantiam a continuidade de estudos em nível de pós-graduação e nem mesmo possibilitavam o exercício de funções inerentes às carreiras de nível superior, ficando excluídos de concursos públicos e processos seletivos de grandes empresas.

Esse Decreto sequer contribuiu para o seu principal objetivo de atender às demandas do mercado de trabalho nesse nível tecnológico, uma vez que o mercado tinha grande rejeição por essa formação, principalmente por desconhecêla, já que não foram desenvolvidas grandes campanhas de divulgação ou políticas públicas de fortalecimento dos CSTs em todo o Governo FHC.

Apesar da falta de políticas públicas, os CSTs foram, de certo modo, um elemento propulsionador das matrículas no ensino superior brasileiro com grande participação do setor privado.

Também em 1997, no dia 24 de novembro, foi assinado o acordo de empréstimo e o contrato n. 1052 com o Banco Interamericano de Desenvolvimento (BID), no valor de 250 milhões de dólares, acrescidos de 125 milhões do orçamento do MEC e 125 milhões do Fundo de Amparo ao Trabalhador (FAT), totalizando 500 milhões de dólares para a criação do Programa de Expansão da Educação Profissional (Proep). Esse Programa tinha por objetivo implantar um novo modelo de educação profissional, com forte aproximação com o mercado e diversidade na oferta, contando com a participação do setor público, privado e de Organizações Não Governamentais (ONGs) para o desenvolvimento das ações educativas.

Essa nova política de educação profissional do País se assemelhava a já desenvolvida na década de 1960 para oferta de cursos superiores de curta duração em sintonia com o mercado e com a elevação da formação tecnológica, atendendo aos indicativos dos órgãos internacionais, novamente 
contando com empréstimo de uma agência internacional. Para isso, tornava-se necessário um aparato legal que garantisse as ações educacionais pretendidas, a forte aproximação com o mercado e a participação da iniciativa privada no desenvolvimento dessas ações mediante convênios e parcerias, promovendo, em grande medida, uma diminuição da participação das instituições federais de ensino do então recém-criado Sistema Nacional de Educação Tecnológica.

Nesse contexto, em outro documento, o Parecer da Câmara de Educação Básica (CEB) do Conselho Nacional de Educação (CNE), Parecer CNE/CEB n. 17, de 03 de dezembro de 1997, foi reafirmado que a educação profissional de nível tecnológico era de nível superior. Da mesma forma que no Decreto n. 2.208/1997, tal definição não surtiu efeito e não resolveu os problemas de continuidade de estudos e de colocação dos egressos desses cursos nos postos de trabalho destinados aos graduados, uma vez que apenas afirmava ser um curso de nível superior, mas sem o equiparar com os cursos de graduação tradicionais. Continuava sendo um curso superior da educação profissional. Esse Parecer (CNE/CEB n. 17/1997) definia: "A educação profissional tecnológica, acessível aos egressos do ensino médio, integra-se à educação superior e regula-se pela legislação referente a esse nível de ensino." (BRASIL, 1997a).

E não foi apenas na definição do nível tecnológico que o Decreto $n$. 2.208/1997 provocou discussões na sociedade e na comunidade acadêmica. Na educação profissional de nível técnico, extinguiu-se a oferta de cursos técnicos que integravam a formação profissional ao ensino médio, restando apenas a possibilidade de oferta de educação profissional independente do ensino médio, na forma concomitante ou subsequente. Em ambas os alunos deveriam ter duas matrículas, uma na educação profissional e outra no ensino médio. Essa definição constava no artigo $5^{\circ}$ do Decreto n. 2.208/1997 (BRASIL, 1997b).

Essa definição extinguia a possibilidade de desenvolvimento de uma educação mais ampla, integral, conforme defendiam Marx e Gramsci em suas propostas, e forçava uma reorganização por completo de todo o currículo dos cursos. A partir daquele momento era exigida a organização focada no desenvolvimento de habilidades e competências, conforme descrito nos artigos $6^{\circ}$ e $7^{\circ}$. 
enfoque na organização das disciplinas, de acordo com as competências e habilidades que deveriam ser desenvolvidas nos alunos, conforme a necessidade do mercado, revela o viés de uma educação voltada para a prática, para a ação, para o saber-fazer, para a tomada de decisão e resolução de problemas. Concordando com Deluiz (1996), tratava-se da mobilização de conhecimentos para a tomada de decisão focada no resultado.

Deluiz (1996) também ressaltava que em razão dessa grande aproximação e organização curricular voltada para as competências, seria possível, ainda, a certificação das competências profissionais alcançadas pelos alunos trabalhadores no desempenho de suas funções nas empresas, o que foi regulamentado no artigo 11 do Decreto.

Sem apresentar definições mais detalhadas de como deveria ser a organização por competências e ao ressaltar a grande aproximação necessária que deveria ser estabelecida com o mercado para sua definição, o Texto Legal expôs o ensino técnico aos três riscos destacados por Deluiz (1996): visão adequacionista da formação, voltada para o atendimento exclusivo das necessidades da reestruturação econômica e das exigências empresariais; abordagem individualizada e individualizante da noção de competência; e preocupação com os resultados (produto) e não com o processo de construção das competências.

Sem maiores indicações no Decreto e sem o amparo de outros documentos legais ou indicativos de como reformular os currículos nesse novo modelo das competências, coube a cada instituição tratar dessa tarefa complexa de acordo com seu entendimento, possibilidades e convicção, incorrendo ou não nesses riscos apontados por Deluiz (1996).

E não apenas no Decreto n. 2.208/ 1997 ficava evidente o compromisso do Governo FHC em adequar a educação às necessidades do mercado de trabalho. Em mais uma ação organizada de acordo com o princípio neoliberal de repassar serviços públicos à iniciativa privada, foi publicada, em 27 de maio de 1998, a Lei n. 9.649 (BRASIL, 1998), que no seu parágrafo $5^{\circ}$ do artigo 47 alterava o artigo $3^{\circ}$ da Lei n. 8.948/1994, incluindo: 
Art. 47 § 5० A expansão da oferta de educação profissional, mediante a criação de novas unidades de ensino por parte da União, somente poderá ocorrer em parceria com Estados, Municípios, Distrito Federal, setor produtivo ou organizações não-governamentais, que serão responsáveis pela manutenção e gestão dos novos estabelecimentos de ensino. (BRASIL, 1998).

Por esse dispositivo, ficava proibida a partir daquele momento a criação de novas unidades na rede federal de educação profissional com recursos públicos da União, sendo admitidos apenas os casos em que a implantação ocorresse mediante convênio, desde a construção até a manutenção e gestão dos novos estabelecimentos de ensino. Essa Lei significou o congelamento da educação profissional no Brasil, limitando o aumento do número de unidades e de matrículas nos diferentes cursos. Associada a outras ações, como o congelamento de concursos públicos de ingresso de servidores para a rede federal e limitação de recursos orçamentários sob o pretexto de que o custo por aluno era muito elevado, o que se viu nos anos seguintes foi a retração da educação profissional pública e o aumento significativo dos segmentos privados e das $\mathrm{ONG}$ s, instituições muito acionadas para desenvolvimento de ações no campo da educação básica e continuada no Governo FHC.

Dando continuidade à reforma da educação profissional no Brasil, no ano 1999 foi publicada a Resolução n. 04/1999 do CNE/CEB (BRASIL, 1999), que instituiu as Diretrizes Curriculares Nacionais para a Educação Profissional de Nível Técnico, trazendo os conceitos de competência profissional e habilidades, a organização por áreas profissionais, entre outras diretrizes para a EPT. Nesse documento ficou reforçado o compromisso com um ensino técnico voltado para a prática, para o saber fazer, com vistas ao atendimento do mercado de trabalho.

A publicação do Decreto n. 2.208/1997 para complementar definições da LDB no campo da EPT, bem como a publicação da Resolução n. 04/1999, evidenciaram a política de governo compromissada com uma 
formação tecnicista ${ }^{8}$ voltada para o mercado de trabalho e flexível de acordo com os interesses econômicos, eliminando a possibilidade de uma formação mais humanística e unitária, por meio de cursos técnicos integrados ao ensino médio e criando um nível tecnológico sem a definição legal de equiparação aos cursos de graduação tradicionais.

Mais adiante, em 2001, cumprindo uma exigência da LDB/1996, que nos seus artigos $9^{\circ}$ e 87 definia que um Plano Nacional de Educação (PNE) deveria ser elaborado pela União em colaboração com os Estados, o Distrito Federal e os Municípios e enviado para o Congresso Nacional em até um ano a partir de sua publicação, constando de diretrizes e metas para os 10 anos seguintes, foi aprovado no legislativo e sancionado por FHC o primeiro PNE mediante a Lei n. 10.172, de 09 de janeiro de 2001 (BRASIL, 2001b), com vigência entre os anos 2001 e 2010.

As metas definidas nesse Plano deveriam ser cumpridas pelo Governo Federal, Estados, Distrito Federal e Municípios, aos quais caberiam, ainda, o planejamento e a execução das ações necessárias para esse cumprimento, inclusive, nos seus planos plurianuais, conforme definido no artigo $5^{\circ}$ da Lei $n$. 10.172/2001 (BRASIL, 2001b).

Anexado ao texto legal, o PNE possuía uma redação detalhada, que iniciava com o histórico de alguns marcos educacionais do Brasil até a elaboração do PNE 2001-2010, passava pelos objetivos e prioridades e, em seguida, trazia para cada nível e modalidade de ensino, e para o magistério da educação básica, um detalhamento contendo diagnóstico, diretrizes, objetivos e metas. Também foi destinado um tópico específico para o financiamento e gestão, incluindo o diagnóstico, as diretrizes, os objetivos e metas, o financiamento e a gestão. Por fim, eram detalhadas as tarefas de acompanhamento e avaliação.

Trazia um retrato de cada nível e modalidade para declarar a situação da educação naquele momento e definia o crescimento ou as melhorias esperadas ao longo ou ao final da década. Os objetivos e as metas eram bem

8 De acordo com Fidalgo e Machado (2000), o adjetivo tecnicista é utilizado para caracterizar ações educativas que priorizam o aprendizado de técnicas de forma sequencial. 
específicos e detalhados em cada item e, por conta desse formato, estavam dispostos em número elevado no PNE 2001-2010.

A EPT era tratada no item 7-Educação Tecnológica e Formação Profissional, englobando nesse ponto os cursos básicos, técnicos e tecnológicos que não haviam sido tratados no item II - Níveis de ensino, sendo abordados, então, no item III - Modalidades de Ensino, não sendo considerada na educação básica nem na educação superior, ou seja, sendo feitos uma avaliação e um planejamento à parte para a EPT.

No diagnóstico inicial da EPT, o Governo afirmava a carência de informação sobre as ações de formação para o trabalho no País. A dificuldade de levantamento desses dados decorria tanto da heterogeneidade das Instituições que a ofereciam: redes federais e estaduais de escolas técnicas, Sistema S, cursos particulares, entre outros, quanto pela diversidade de Programas do Ministério do Trabalho e das Secretarias Estaduais e Municipais.

Plano menciona o problema da oferta reduzida de vagas para a EPT, principalmente na rede pública federal e estadual, fruto de políticas governamentais que outorgavam serviços públicos para oferta na iniciativa privada, sob a justificativa de que os serviços nessa rede eram mais baratos e eficientes. Esse discurso neoliberal pode ser observado claramente na justificativa do pequeno número de vagas ofertadas na rede federal de educação profissional e tecnológica:

maior problema, no que diz respeito às escolas técnicas públicas de nível médio, é que a alta qualidade do ensino que oferecem está associada a um custo extremamente alto para sua instalação e manutenção, o que torna inviável uma multiplicação capaz de poder atender ao conjunto de jovens que procura formação profissional. Além disso, em razão da oferta restrita, criou-se um sistema de seleção que tende a favorecer os alunos de maior renda e melhor nível de escolarização, afastando os jovens trabalhadores, que são os que dela mais necessitam. (BRASIL, 200lb).

Essa passagem do PNE revela novamente um problema recorrente no sistema educacional brasileiro: a dualidade educacional que separa para os 
mais pobres a educação profissional e a oferta de um ensino público de baixa qualidade e baixo custo. Claramente o Governo federal afirma que para ofertar um ensino de alta qualidade o custo é muito elevado, o que impede o crescimento dos investimentos da rede para atendimento a um maior número de pessoas. Também aponta que essa educação estaria servindo a um público de melhores condições financeiras, que poderia pagar pelos seus estudos, deixando de se matricular no ensino privado e diminuindo os lucros dessas empresas. Fica evidente a defesa de um ensino de pior qualidade e de menor custo para atendimento aos alunos de menor renda e menor nível de escolarização, uma escola profissional mais barata para os pobres. Reforçava mais uma vez o que já havia indicado quando da publicação da Lei n. 9.649/1998.

Aponta como caminho o investimento em cursos rápidos, de curta duração e baixo custo, cursos de educação continuada, sob responsabilidade do trabalhador, como parte de uma política neoliberal que o responsabiliza pelo seu sucesso ou fracasso. Caberia a ele se manter atualizado e progredir nos estudos, que, de acordo com a política então vigente, não precisariam ser de nível médio, mas simplesmente de formação básica, uma educação continuada. E sendo uma formação básica, menores seriam os custos dessa mão de obra no mercado de trabalho. Conforme as diretrizes do Plano, "entendese que a educação profissional não pode ser concebida apenas como uma modalidade de ensino médio, mas deve constituir educação continuada, que perpassa toda a vida do trabalhador." (BRASIL, 200lb).

Para a implantação desse novo modelo de educação profissional, a partir da Reforma do Ensino Médio e de outras políticas educacionais, o Governo federal esperava aumentar o número de vagas nos cursos de formação continuada, com a participação tanto do sistema público quanto do privado, com a integração dos dois tipos de formação: formal e não formal. Uma política de baixo custo que favorecia a rede de ensino privada e as organizações não governamentais e desmantelava ainda mais as instituições públicas federais.

Foram então estipulados 15 objetivos e metas para a EPT, mas nenhuma delas tratava diretamente dos cursos de nível tecnológico. Os CSTs eram tratados indiretamente apenas nas metas 2 e 8 : 
2. Estabelecer a permanente revisão e adequação às exigências de uma política de desenvolvimento nacional e regional, dos cursos básicos, técnicos e superiores da educação profissional, observadas as ofertas do mercado de trabalho, em colaboração com empresários e trabalhadores nas próprias escolas e em todos os níveis de governo.

8. Estabelecer, com a colaboração entre o Ministério da Educação, o Ministério do Trabalho, as universidades, os CEFETs, as escolas técnicas de nível superior, os serviços nacionais de aprendizagem e a iniciativa privada, programas de formação de formadores para a educação tecnológica e formação profissional. (BRASIL, 200lb).

A maioria das metas era destinada aos cursos básicos de formação continuada e à ampliação da rede de instituições de educação profissional. Importante observar que não existia a defesa da ampliação da rede pública de educação profissional. Pelo modelo proposto no PNE 2001-2010, conforme meta 10, a ampliação da oferta de educação profissional aconteceria sempre a partir das parcerias entre os sistemas federal, estaduais e municipais e a iniciativa privada, não havendo qualquer previsão de ampliação do número de instituições públicas federais de educação profissional (152 até a publicação do Plano) ou do número de vagas ofertadas nessas instituições. Em resumo, o PNE 2001-2010 esboçava um futuro sombrio para a EPT no Brasil.

Em abril do mesmo ano de publicação do PNE 2001-2010, a Câmara de Educação Superior (CES) do CNE deu um primeiro passo em direção à equiparação dos CSTs com os cursos de graduação tradicionais ao emitir o Parecer CNE/CES n. 436, de 02 de abril de 2001 (BRASIL, 200 la).

Nesse Parecer, a comissão instituída pela CES considerou as possibilidades de os CSTs serem enquadrados como cursos pós-médios, cursos superiores sequenciais ou como cursos de graduação. Porém, ao analisar suas características, decidiram pela classificação como cursos de graduação.

Apesar de considerar que os CSTs deveriam ser classificados como cursos de graduação, fizeram uma ressalva de que, apesar da equiparação, necessitariam do estabelecimento de suas características específicas de modo a distingui-los dos demais cursos de graduação existentes, ou seja, sem absorver 
todas as prerrogativas já associadas aos cursos tradicionais, como o exercício da profissão e o registro em conselhos de classe, por exemplo. Essa ressalva de exceção parece reconhecer os CSTs como de graduação, mas ao mesmo tempo revela o lugar secundário destinado a eles no ensino superior brasileiro, ratificando as críticas sobre a existência de uma educação dual.

E na emissão de parecer final, concluía que:

Os Cursos Superiores de Tecnologia são cursos de graduação com características especiais, bem distintos dos tradicionais e cujo acesso se fará por processo seletivo, a juízo das instituições que os ministrem. Obedecerão a Diretrizes Curriculares Nacionais a serem a aprovadas pelo Conselho Nacional de Educação. (BRASIL, 200 la, p. 14);

No entanto, efetivamente essa equiparação somente foi feita no final do Governo FHC, em dezembro de 2002, por intermédio do Conselho Pleno do CNE na publicação do Parecer CNE/CP n. 29 (BRASIL, 2002a) e de sua respectiva Resolução n. 3 (BRASIL, 2002b). Destaca-se o longo período, entre abril de 2001, quando foi estabelecida a necessidade de elaboração das Diretrizes Curriculares Nacionais (DCNs) para os CSTs, e a sua efetiva aprovação apenas em dezembro de 2002.

A Resolução n. 3, de 18 de dezembro de 2002, instituiu as Diretrizes Curriculares Nacionais Gerais para a organização e o funcionamento dos CSTs. Em termos estruturais e de concepção, guarda grande semelhança com a Resolução n. 04/1999 do CNE/CEB, que instituiu as Diretrizes Curriculares Nacionais para a Educação Profissional de Nível Técnico. $\bigcirc$ conceito de competência apresentado no artigo $7^{\circ}$ da Resolução n. 3/2002 se assemelha bastante ao definido no artigo $6^{\circ}$ da Resolução n. 04/1999, reafirmando o compromisso com o mercado e com uma formação para o saber fazer, para a prática, também nos CSTs.

Essa Resolução, apesar de esclarecer alguns pontos importantes não abordados ou definidos de forma insuficiente nos dispositivos legais analisados anteriormente que tratavam dos CSTs, acabou por reforçar os princípios de uma educação rápida e flexível voltada para o mercado de trabalho, que 
privilegiava o saber fazer e parecia não considerar os embates da academia e da sociedade, que teciam diversas críticas ao modelo implantado, e nem mesmo as considerações da Senete, que havia documentado os principais problemas encontrados na oferta da graduação tecnológica no Brasil até o início dos anos 1990.

Logo no seu artigo $2^{\circ}$, definia a designação dada aos cursos superiores ofertados no nível tecnológico e elencava seus principais objetivos:

\begin{abstract}
Art. $2^{\circ}$ Os cursos de educação profissional de nível tecnológico serão designados como cursos superiores de tecnologia e deverão:

I - incentivar o desenvolvimento da capacidade empreendedora e da compreensão do processo tecnológico, em suas causas e efeitos;

II - incentivar a produção e a inovação científicotecnológica, e suas respectivas aplicações no mundo do trabalho:

III - desenvolver competências profissionais tecnológicas, gerais e específicas, para a gestão de processos e a produção de bens e serviços;

IV - propiciar a compreensão e a avaliação dos impactos sociais, econômicos e ambientais resultantes da produção, gestão e incorporação de novas tecnologias;

$\mathrm{V}$ - promover a capacidade de continuar aprendendo e de acompanhar as mudanças nas condições de trabalho, bem como propiciar o prosseguimento de estudos em cursos de pós-graduação;

VI - adotar a flexibilidade, a interdisciplinaridade, a contextualização e a atualização permanente dos cursos e seus currículos;

VII - garantir a identidade do perfil profissional de conclusão de curso e da respectiva organização curricular. (BRASIL, 2002b).
\end{abstract}

Por se tratar de uma educação na área de tecnologia, definia entre esses objetivos o caráter da continuidade da formação em busca da atualização constante dos currículos e reforçava o seu compromisso com o mercado, ressaltando logo no inciso primeiro o incentivo à capacidade empreendedora nos alunos desses cursos, ação sistematizada e valorizada pelo MEC durante os Governos FHC. Nesse período, era forte o incentivo para a formação imediata para o mercado de trabalho ou o empreendimento do próprio negócio como alternativa à falta de emprego formal no País. A responsabilidade passava, 
então, de acordo com a lógica neoliberal, a ser dos próprios trabalhadores, que, ao não conseguirem um emprego formal, deveriam tentar abrir seu próprio negócio. Nos diferentes níveis da educação profissional, não era observado o objetivo de elevar o nível de escolaridade da população, mas o atendimento imediato às necessidades do mercado.

Em virtude dessa grande investida do Governo federal na formação empreendedora é que foram criadas disciplinas de empreendedorismo e, em alguns casos, mantidas até hoje, nas matrizes curriculares dos CSTs.

Retomando a análise da Resolução CNE/CP n. 3/2002, no artigo 3 , ao definir os critérios para o planejamento e a organização dos CSTs, destacase o atendimento ao "mercado de trabalho", ao contrário do estabelecido no Decreto n. 2.208/ 1997, que utilizava "mundo do trabalho" de forma equivocada.

Art. $3^{\circ}$ São critérios para o planejamento e a organização dos cursos superiores de tecnologia:

I - o atendimento às demandas dos cidadãos, do mercado de trabalho e da sociedade;

II - a conciliação das demandas identificadas com a vocação da instituição de ensino e as suas reais condições de viabilização;

III - a identificação de perfis profissionais próprios para cada curso, em função das demandas e em sintonia com as políticas de promoção do desenvolvimento sustentável do País. (BRASIL, 2002b).

Cumprindo um papel importante, mesmo que de forma tardia, já no apagar das luzes do Governo FHC, definiu a equiparação com os cursos de graduação, no seu artigo $4^{\circ}$, e determinou outros pontos específicos ao planejamento e funcionamento desses cursos no que tange à menção às competências profissionais, ao perfil do curso, ao histórico escolar, ao acréscimo do tempo de estágio na carga horária e à menção da carga horária e plano de estágio nos projetos pedagógicos dos cursos.

Como ocorria com os cursos técnicos, determinou-se que os CSTs deveriam promover a organização curricular em módulos, com possibilidade de certificação parcial correspondente, garantindo uma maior flexibilidade e terminalidade intermediária para atendimento às necessidades do mercado, 
conforme definido no artigo 5\%, no qual é utilizado de forma equivocada o termo "mundo do trabalho", da mesma forma que já fora identificado no Decreto n. 2.208/1997. No caso dessa resolução em específico, identificou-se a utilização tanto de "mundo do trabalho" quanto de "mercado de trabalho" de forma indistinta, sinalizando pouca aproximação com o campo teórico na definição de sua concepção de educação.

Ainda na Resolução n. 3/2002, no seu artigo 6, é estabelecido como deveria ser a organização por competências, como o modelo adotado nos cursos técnicos.

Apesar de no parágrafo $1^{\circ}$ do artigo $6^{\circ}$ ficar estabelecido que a organização curricular compreenderá as competências profissionais tecnológicas, gerais e específicas, incluindo os fundamentos científicos e humanísticos necessários ao desempenho profissional do graduado em tecnologia, não são observadas definições complementares que determinem os referenciais mínimos desejados para cada fundamento indicado, permitindo o desenvolvimento de propostas voltadas prioritariamente para o mercado, para o saber fazer, o ensino focado na ação, na competência, na resolução de problemas, com bases científica e humanística abreviadas.

Ainda no bojo das competências, no artigo $9^{\circ}$ é facultado o aproveitamento de competências profissionais anteriormente desenvolvidas, estreitando novamente a relação do ensino com o mercado de trabalho para o aproveitamento de competências que poderiam ter sido desenvolvidas no desempenho de atividades profissionais no trabalho ou em outros programas de estudos.

Outro aspecto importante abordado nessa resolução foi a necessidade por parte das instituições de ensino de observarem as atribuições das profissões regulamentadas em lei ao elaborarem seus projetos pedagógicos de curso, conforme descrito no artigo 10.

No entanto, não foram desenvolvidas ações governamentais durante o Governo FHC no sentido de promover avanços no ponto principal dessa questão: a aprovação da regulamentação da profissão de tecnólogo e a intervenção junto aos conselhos de classe para garantir a filiação dos 
profissionais nesses conselhos e as suas atribuições para desempenho das profissões de acordo com o perfil de conclusão definido nos planos de curso. A definição desse artigo parece ser muito mais no sentido de que os CSTs não buscassem a formação com prerrogativas de profissões já regulamentadas do que regulamentar as atribuições da profissão de tecnólogo, o que mais uma vez criava um ponto de exclusão desses profissionais.

Em relação ao corpo docente, ao equiparar os CSTs aos cursos tradicionais de graduação, também definiu, no artigo 12 da Resolução n. 3/2002, que a formação mínima dos professores para atuação nesses cursos deveria ser a mesma praticada no ensino superior, conforme definido na LDB. E no artigo 13, revelando a grande valorização de profissionais que já atuavam no mercado e desempenhavam também a função de professores, como proposto pela Senete (BASTOS, 1991b), estabelecia que a competência e a experiência técnica na área dos professores das disciplinas da formação profissional deveriam ter a mesma ponderação da avaliação da qualidade com requisito acadêmico.

Esses artigos concretizaram a defesa antiga da Senete de aproveitar os profissionais do mercado como professores nos CSTs, mas, com a equiparação aos requisitos dos cursos de graduação tradicionais, conforme previsto na LDB/1996, passou-se a requerer as mesmas exigências mínimas.

Mas se por um lado a formação mínima acadêmica era exigida, por outro, ao avaliar a qualidade dos cursos (em processos de reconhecimento ou de renovação de reconhecimento pelo $\mathrm{MEC}$ ), a experiência profissional nas áreas de atuação das disciplinas profissionais teria o mesmo peso da formação acadêmica nas disciplinas gerais ou propedêuticas, o que não se aplicava, por exemplo, nas avaliações de qualidade dos cursos de engenharia, que possui grande parte de componentes curriculares nas áreas profissionais de formação. Essa avaliação de qualidade desigual revela que, apesar de equiparados aos cursos tradicionais, são reconhecidas algumas particularidades dos CSTs no que tange à formação dos professores que atuam nesses cursos. Pelo exposto, desde a publicação das DCNs, os CSTs foram permitidos formalmente a terem um corpo docente com maior experiência profissional no trabalho em vez de uma maior formação acadêmica. 
Ao analisar as políticas de educação profissional no Governo FHC, partilhamos com a conclusão de Brandão (2013) ao associar tais políticas às desenvolvidas nas décadas de 1960 e 1970 tanto na educação profissional técnica de nível médio quanto na então educação de nível tecnológico. No primeiro mandato de $\mathrm{FHC}$ a educação profissional técnica foi tratada como uma alternativa ao ensino superior nos remetendo à Lei n. 5.692/1971. ${ }^{9} \mathrm{E}$ no segundo mandato esse papel coube à educação profissional de nível tecnológico, oficializando a distinção entre o ensino superior acadêmico e profissionalizante. Ela, ainda, destaca que tais estratégias favoreceram as instituições privadas de ensino superior, que apresentaram acentuado crescimento desses cursos em 2003.

Apesar de resolver em parte algumas questões que traziam dúvidas quanto à formação de tecnólogos, o fato de ser uma resolução e de se manterem inalterados a LBD/1996 e o Decreto n. 2.208/1997, associado à falta de divulgação e de implementação de políticas para consolidação da carreira de tecnólogo nas diferentes áreas, pequena foi a efetividade imediata da Resolução n. 3/2002, sendo necessário o desenvolvimento de outras ações e de solução dos problemas identificados desde o início da década de 1990 pela Senete e de outros que surgiram ao longo da retomada da oferta, da criação do Sistema Nacional de Educação Tecnológica e da vertiginosa expansão do ensino superior no Brasil.

\section{CONSIDERAÇÕES FINAIS}

A partir da análise realizada nesta pesquisa foi possível constatar que em todo o período estudado o modelo legal proposto para os CSTs promovia uma educação voltada para o mercado de trabalho, a partir de uma formação

\footnotetext{
9 A Lei n. 5.692, de 11 de agosto de 1971, fixou as "Diretrizes e Bases para o ensino de $1^{\circ}$ e $2^{\circ}$ graus" e estabeleceu a obrigatoriedade de esse nível de ensino oferecer uma habilitação profissional.
} 
intermediária posicionada entre os cursos técnicos de nível médio e os cursos de graduação.

A retomada da oferta dos CSTs pelos Governos FHC revelou, ainda, um modelo de política pública que parecia trazer a execução antes do planejamento, o que ocasionou efeitos desastrosos: baixa aceitação dos profissionais formados; dificuldade para continuidade dos estudos acadêmicos em nível de pós-graduação e para ocupação das suas funções profissionais de trabalho, uma vez que a oferta dos cursos aconteceu antes mesmo da sua completa regulação.

A falta de regulação, ao que parece, foi parte da estratégia de oferecer esses cursos nos moldes dos propostos pela Fundação Ford, retomados a partir do Proep com a concepção de uma formação intermediária, sequencial e de curta duração. No entanto, essa ausência de dispositivos regulatórios até mesmo para indicar que essa modalidade não conferia diploma de graduação, trouxe grande incerteza e uma forte pressão, uma vez que os velhos problemas encontrados nas décadas de 1960 a 1980 resurgiram (e deve-se atentar que boa parte deles já havia sido identificada pela Senete e elaboradas algumas proposições (BASTOS, 1991b)) e fizeram com que o Governo mostrasse uma pequena reação no sentido de melhor definir os aspectos ligados a essa formação, no final do mandato de FHC. Pequenas e tardias ações diante de tantos problemas encontrados e da necessidade urgente de soluções que valorizassem a formação e a profissão de tecnólogo, algo observado e atendido parcialmente apenas nos anos seguintes, já no Governo Lula.

\section{REFERÊNCIAS}

BASTOS, J. A. S. L. A. A Educação Técnico-Profissional: fundamentos, perspectivas e prospectiva. Brasília, DF: Senete/MEC, 1991 a.

BASTOS, J. A. S. L. A. Curso Superior de Tecnologia: avaliação e perspectivas de um modelo de educação técnico-profissional. Brasília, DF: Senete/ MEC, $1991 \mathrm{~b}$. 
BRANDÃO, M. Cursos superiores de tecnologia: uma formação intermediária. In: MOURA, D. H. (Org.). Produção de conhecimento, políticas públicas e formação docente em educação profissional. l. ed. Campinas: Mercado de Letras, 2013. p. 307-346.

BRASIL. Conselho Nacional de Educação. Câmara de Educação Básica. Parecer n. 17, de 03 de dezembro de 1997. Diretrizes operacionais para a educação profissional em nível nacional. Diário Oficial da União, Brasília, DF, 03 dez. 1997a. Disponível em: <http://portal.mec.gov.br/cne/arquivos/ pdf/1997/pceb017_97.pdf>. Acesso em: 19 jun. 2017.

BRASIL. Conselho Nacional de Educação. Câmara de Educação Superior. Parecer n. 436, de 02 de abril de 2001. Cursos Superiores de Tecnologia - Formação de Tecnólogos. Diário Oficial da União, Brasília, DF, 02 abr. 2001 a. Disponível em: <http://portal.mec.gov.br/cne/arquivos/pdf/CES0436. pdf $>$. Acesso em: 19 jun. 2017.

BRASIL. Conselho Nacional de Educação. Conselho Pleno. Parecer n. 29, de 02 de dezembro de 2002. Diretrizes Curriculares Nacionais Gerais para a Educação Profissional de Nível Tecnológico. Diário Oficial da União, Brasília, DF, 02 dez. 2002a. Disponível em: <http://portal.mec.gov.br/cne/arquivos/ pdf/cp29.pdf>. Acesso em: 19 jun. 2017.

BRASIL. Conselho Nacional de Educação. Câmara de Educação Básica. Resolução n. 4, de 05 de outubro de 1999. Institui as Diretrizes Curriculares Nacionais para a Educação Profissional de Nível Técnico. Diário Oficial da União, Brasília, DF, 05 out. 1999. Disponível em: <http://portal.mec.gov.br/ setec/arquivos/pdf/RCNE_CEB04_99.pdf>. Acesso em: 19 jun. 2017.

BRASIL. Conselho Nacional de Educação. Conselho Pleno. Resolução n. 3, de 18 de dezembro de 2002. Institui as Diretrizes Curriculares Nacionais Gerais para a organização e o funcionamento dos cursos superiores de tecnologia.

Diário Oficial da União, Brasília, DF, 18 dez. 2002b. Disponível em: < http:// portal.mec.gov.br/cne/arquivos/pdf/CP032002.pdf>. Acesso em: 19 jun. 2017.

BRASIL. Decreto n. 2.208, de 17 de abril de 1997. Regulamenta o $\$ 2^{\circ}$ do art. 36 e os arts. 39 a 42 da Lei n. 9.394, de 20 de dezembro de 1996, que estabelece as diretrizes e bases da educação nacional. Diário Oficial da União, Brasília, DF, 17 abr. 1997b. Disponível em: < https://www.planalto.gov. br/ccivil_03/decreto/d2208.htm>. Acesso em: 19 jun. 2017. 
BRASIL. Decreto n. 2.406, de 27 de novembro de 1997. Regulamenta a Lei n. 8.948, de 08 de dezembro de 1994, e dá outras providências. Diário Oficial da União, Brasília, DF, 27 nov. 1997c. Disponível em: < http://www.planalto. gov.br/ccivil_03/decreto/Antigos/D2406.htm>. Acesso em: 19 jun. 2017.

BRASIL. Decreto n. 87.310, de 21 de junho de 1982. Regulamenta a Lei n. 6.545, de 30 de junho de 1978, e dá outras providências. Diário Oficial da União, Brasília, DF, 21 jun. 1982. Disponível em: <http://www.planalto.gov. br/ccivil_03/decreto/1980-1989/D87310.htm>. Acesso em: 19 jun. 2017.

BRASIL. Lei n. 5.540, de 28 de novembro de 1968. Fixa normas de organização e funcionamento do ensino superior e sua articulação com a escola média, e dá outras providências. Diário Oficial da União, Brasília, DF, 28 nov. 1968. Disponível em: <http://www2.camara.leg.br/legin/fed/lei/1960-1969/ lei-5540-28-novembro-1968-35920l-publicacaooriginal-l-pl.html>. Acesso em: 19 jun. 2017.

BRASIL. Lei n. 6.344, de 06 de julho de 1976. Cria o Centro de Educação Tecnológica da Bahia e dá outras providências. Diário Oficial da União, Brasília, DF, 06 jul. 1976. Disponível em: <http://www.planalto.gov.br/ccivil_03/ leis/1970-1979/L6344.htm>. Acesso em: 19 jun. 2017.

BRASIL. Lei n. 6.545, de 30 de julho de 1978. Dispõe sobre a transformação das Escolas Técnicas Federais de Minas Gerais, do Paraná e Celso Suckow da Fonseca em Centros Federais de Educação Tecnológica e dá outras providências. Diário Oficial da União, Brasília, DF, 30 jul. 1978. Disponível em: $<$ https://www.planalto.gov.br/ccivil_03/LEIS/L6545.htm>. Acesso em: 19 jun. 2017.

BRASIL. Lei n. 8.71 l, de 28 de setembro de 1993. Dispõe sobre a transformação da Escola Técnica Federal da Bahia em Centro Federal de Educação Tecnológica e dá outras providências. Diário Oficial da União, Brasília, DF, 28 set. 1993. Disponível em: <http://www.planalto.gov.br/ccivil_03/ leis/1989_1994/L871l.htm>. Acesso em: 19 jun. 2017.

BRASIL. Lei n. 8.948, de 08 de dezembro de 1994. Dispõe sobre a instituição do Sistema Nacional de Educação Tecnológica e dá outras providências. Diário Oficial da União, Brasília, DF, 08 dez. 1994. Disponível em: <http://www. planalto.gov.br/ccivil_03/leis/L8948.htm>. Acesso em: 19 jun. 2017.

BRASIL. Lei n. 9.394, de 20 de dezembro de 1996. Estabelece as diretrizes e bases da educação nacional. Diário Oficial da União, Brasília, DF, 20 dez. 1996. Disponível em: <http://www.planalto.gov.br/ccivil_03/leis/19394.htm>. Acesso em: 19 jun. 2017. 
BRASIL. Lei n. 9.649, de 27 de maio de 1998. Dispõe sobre a organização da Presidência da República e dos Ministérios, e dá outras providências. Diário Oficial da União, Brasília, DF, 27 maio 1998. Disponível em: <http://www. planalto.gov.br/ccivil_03/Leis/L9649cons.htm>. Acesso em: 19 jun. 2017.

BRASIL. Lei n. 10.172, de 09 de janeiro de 2001. Aprova o Plano Nacional de Educação e dá outras providências. Diário Oficial da União, Brasília, DF, 09 jan. 200lb. Disponível em: <http://www.planalto.gov.br/ccivil_03/leis/ leis_2001/110172.htm>. Acesso em: 19 jun. 2017.

DELUIZ, N. A globalização econômica e os desafios à formação profissional. Boletim Técnico do SENAC, Rio de Janeiro, v. 22, n. 2, maio/ago. 1996. Disponível em: <http://www.senac.br/BTS/222/boltec222b.htm> . Acesso em: 19 jun. 2017.

FIDALGO, F; MACHADO, L. Dicionário da educação profissional. Belo Horizonte: Núcleo de Estudos sobre Trabalho e Educação, 2000.

GRAMSCI, A. Os intelectuais e a organização da cultura. 2. ed. Rio de Janeiro: Civilização Brasileira, 1978.

KUENZER, A. Z. Ensino Médio e profissional: as políticas do Estado neoliberal. 4. ed. São Paulo: Cortez, 2007.

Recebido em 27 de novembro de 2017 Aceito em 03 de abril de 2018

Endereços para correspondência: Rua Alvarenga Prazeres, n. 213, Donana, 281 10-000, Campos dos Goytacazes, Rio de Janeiro, Brasil; anthone.mateus@ gmail.com 